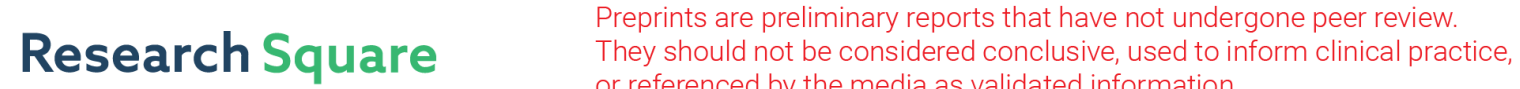 or referenced by the media as validated information. \\ Polarization Domain Dynamics of Barium Titanate Ultrathin Films Using Piezoresponse Force Microscopy.
}

gregory salamo ( $\square$ salamo@uark.edu )

University of Arkansas Fayetteville

Mohammad Zamani-Alavijeh

University of Arkansas Fayetteville

Timothy Morgan

University of Arkansas Fayetteville

Andrian Kuchuk

University of Arkansas Fayetteville

\section{Nano Express}

Keywords: Polarization, dynamics, microscopy

Posted Date: March 22nd, 2021

DOI: https://doi.org/10.21203/rs.3.rs-315398/v1

License: (c) (i) This work is licensed under a Creative Commons Attribution 4.0 International License.

Read Full License 


\section{Abstract}

Piezoresponse force microscopy is used to study the velocity of the polarization domain wall in ultrathin ferroelectric barium titanate films grown on strontium titanate substrates by molecular beam epitaxy. The electric field due to the cone of the atomic force microscope tip is proposed as the dominant electric field of the tip in thin films for domain expansion at lateral distances greater than about one tip diameter away from the tip. The velocity of the domain wall under the applied electric field by the tip in barium titanate for thin films (less than $40 \mathrm{~nm}$ ) followed an expanding process given by Merz's law. The material constants in a fit of the data to Merz's law for very thin films are reported as about $4.2 \mathrm{KV} / \mathrm{cm}$ for activation field, Ea, and $0.05 \mathrm{~nm} / \mathrm{s}$ for limiting velocity, $\mathrm{v} \infty$. These material constants showed a dependence on the level of strain in the films but no fundamental dependence on thickness.

\section{Full Text}

This preprint is available for download as a PDF.

\section{Figures}
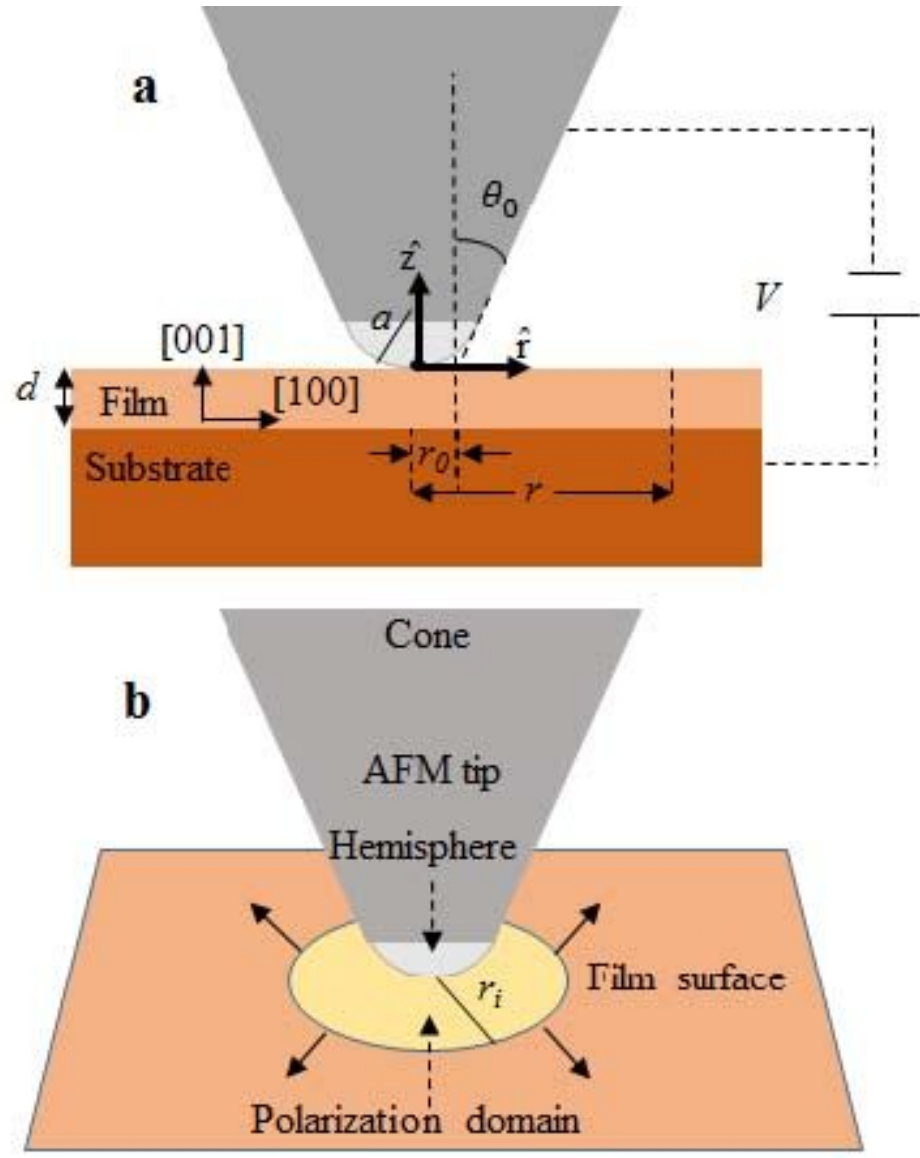

Figure 1 
(a) For the conductive AFM tip-ferroelectric film-conductive substrate, the origin is at the tip-surface contact point; $\mathrm{V}$ is the applied voltage; $\mathrm{a}$, the tip apex radius; $\mathrm{r}$, is the distance from the origin; $\mathrm{r} 0$, the distance between the intercept of the cone with the surface and the origin; $d$, the thickness of the film; and $\theta 0$, the cone half angle. [001] is the c-direction of the film and [100] the a-direction.(b) Polarization domain expands over time under the electric field applied by the AFM tip. ri is about a tip diameter away from the origin and is where the electric field due to the cone dominates.

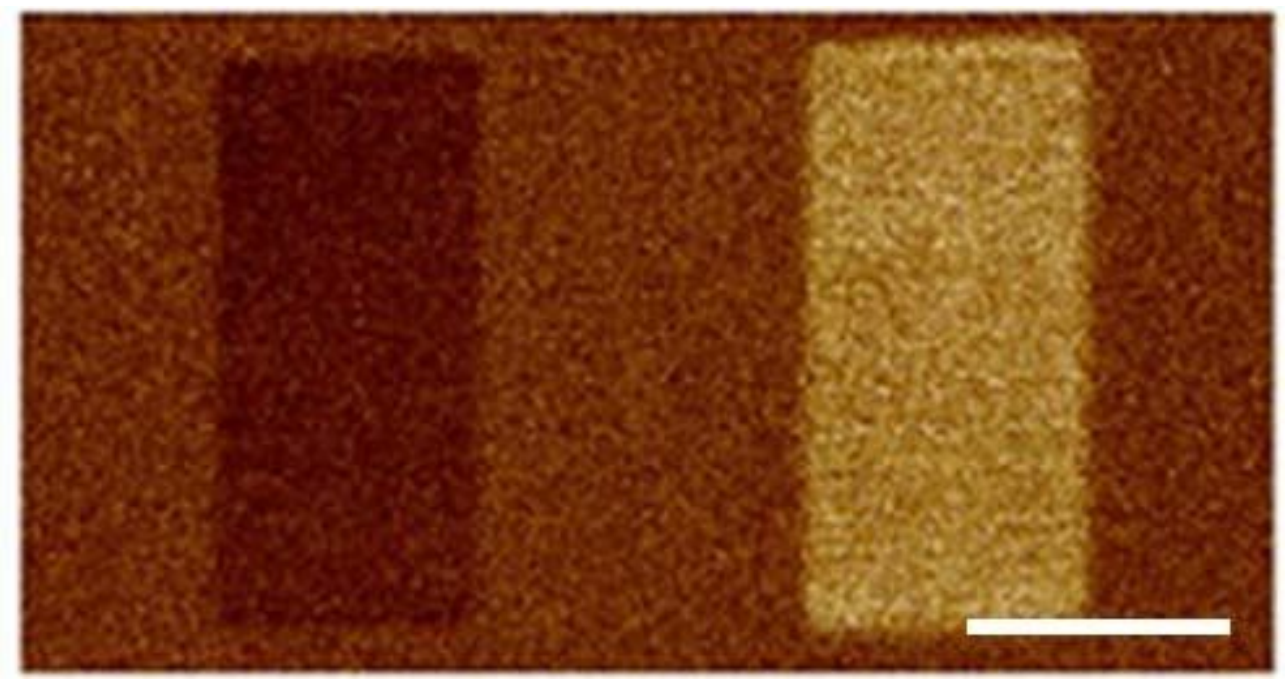

\section{Figure 2}

The downward [00-1] domain on left is formed by scanning $-4 \mathrm{~V}$, and upward [001] domain on right is formed by scanning $+4 \mathrm{~V}$. The white line on the figure is $1 \mu \mathrm{m}$.

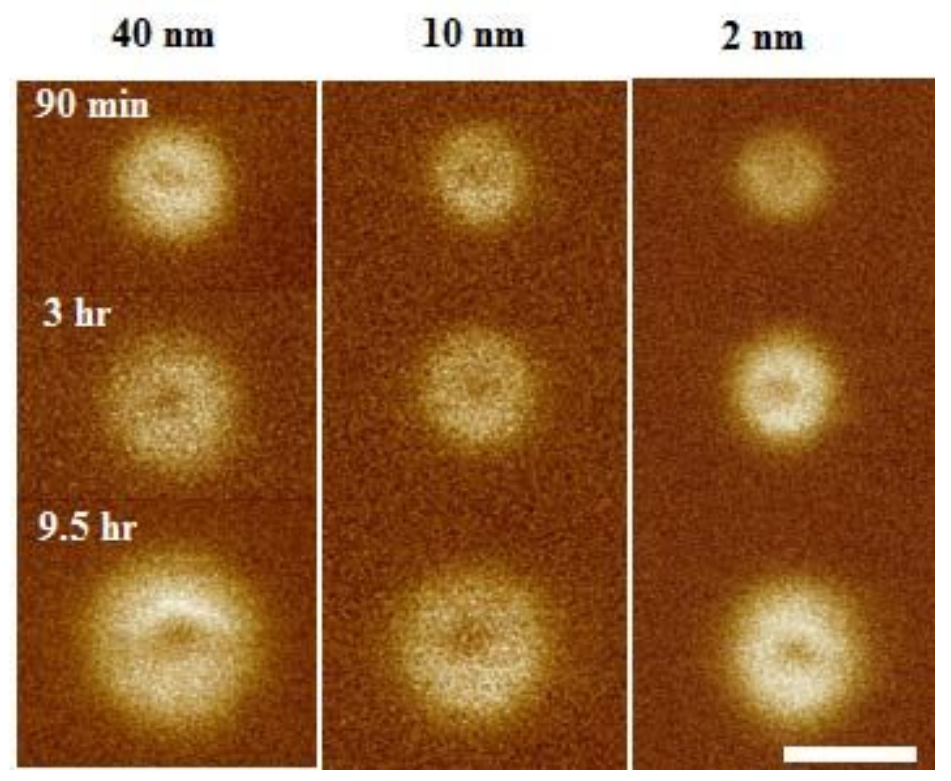

\section{Figure 3}

Polarization domain of [001] poled domains on 2, 10, and $40 \mathrm{~nm}$ BTO films as a function of time after poling with $7 \mathrm{~V}$ by tip \#1. The white line on the figure is $400 \mathrm{~nm}$. 


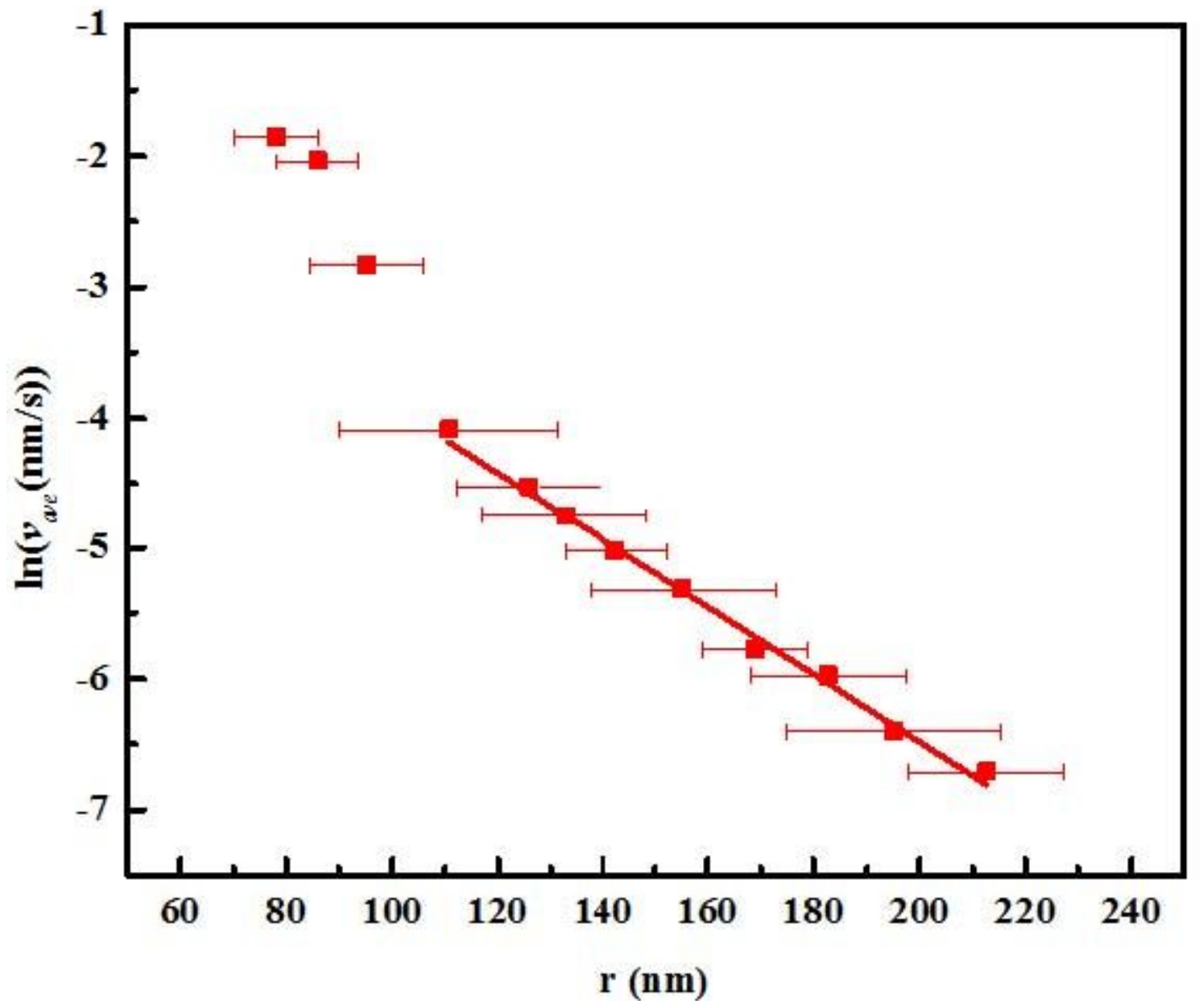

Figure 4

Logarithm of the average velocity of domain wall, vave verses $r$ on $10 \mathrm{~nm}$ film using tip \#1. 
$\mathbf{a}$

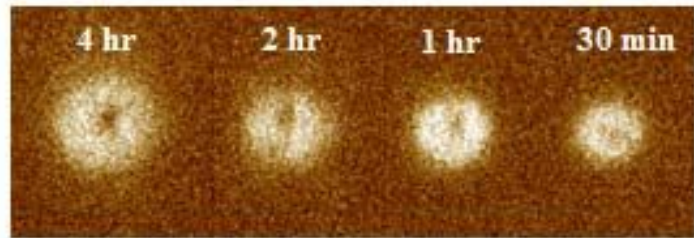

8 volts

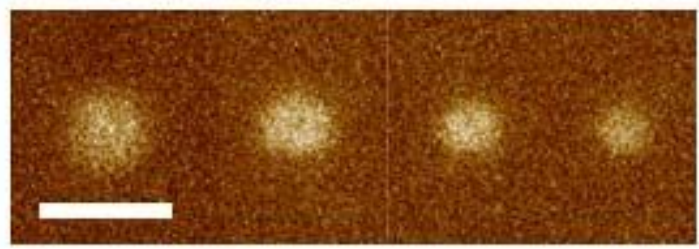

4 rolts

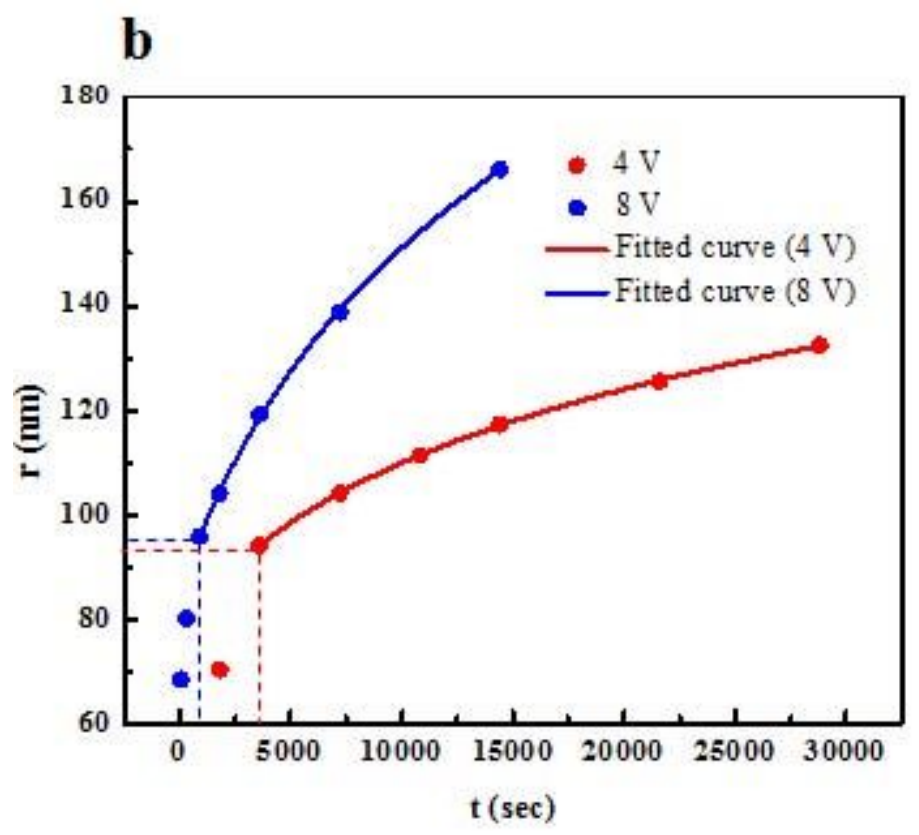

Figure 5

(a) Polarization domains for two applied voltages using tip\#2; The white line on the figure is $400 \mathrm{~nm}$; (b) Radius of domains, $r$, as a function of time of poling, $t$ using 4 and $8 \mathrm{~V}$. The data fit well to the Eq. 6 for $r$ and $t$ greater than ri and ti. 


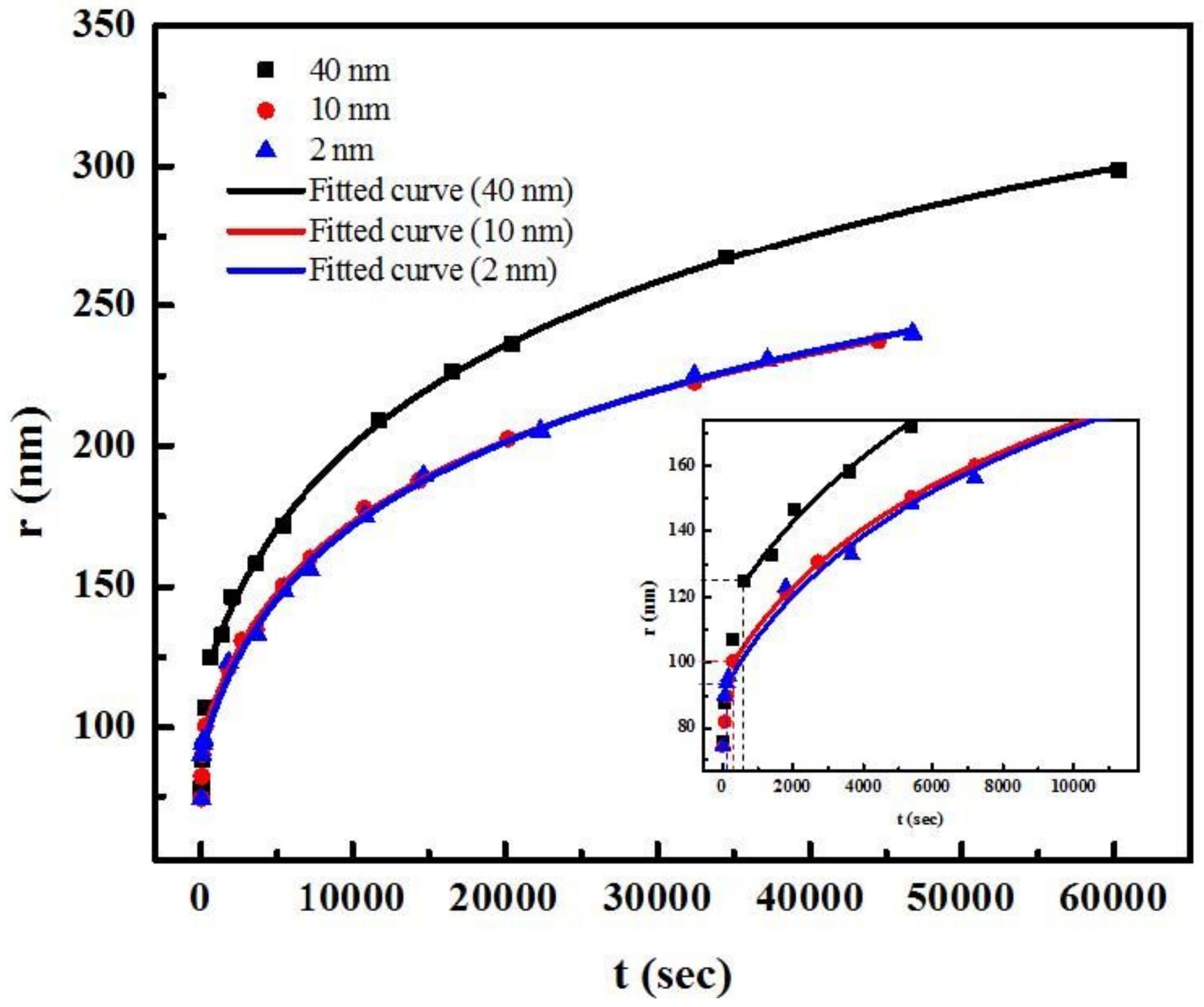

Figure 6

Radius of domains, $r$, vs. time of poling, $t$ on $2,10,40 \mathrm{~nm}$ films using tip\#1 applying $7 \mathrm{~V}$. The data is accurately predicted by Eq. 6 for lateral distances greater than about one tip diameter from the tip. 

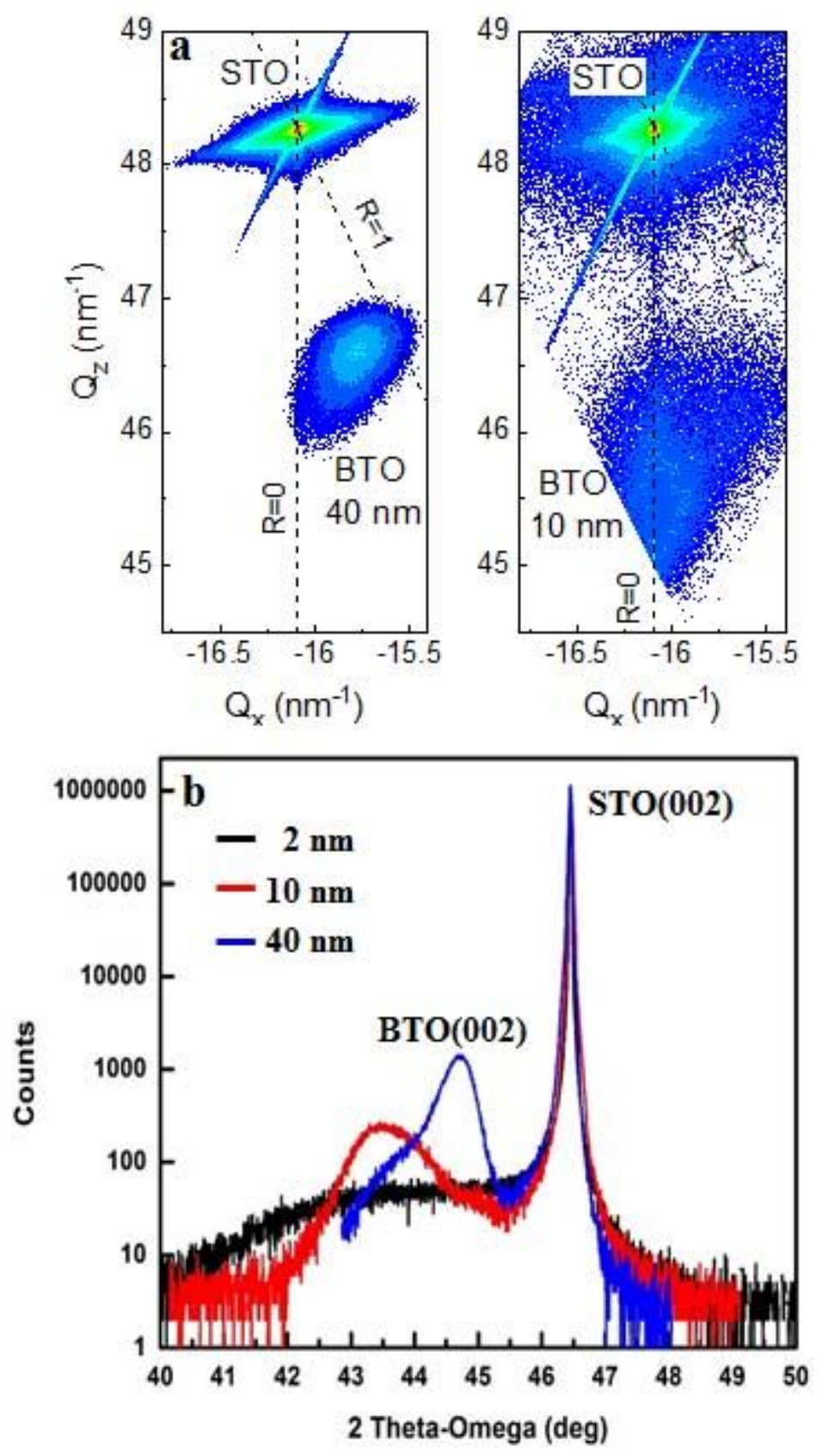

Figure 7

Reciprocal lattice map of 10 and $40 \mathrm{~nm}$ films, (b) XRD 2 Theta-Omega of 2, 10, $40 \mathrm{~nm}$ films, (measured with Panalytical Materials Research Diffractrometer with Cu ka x-rays). 


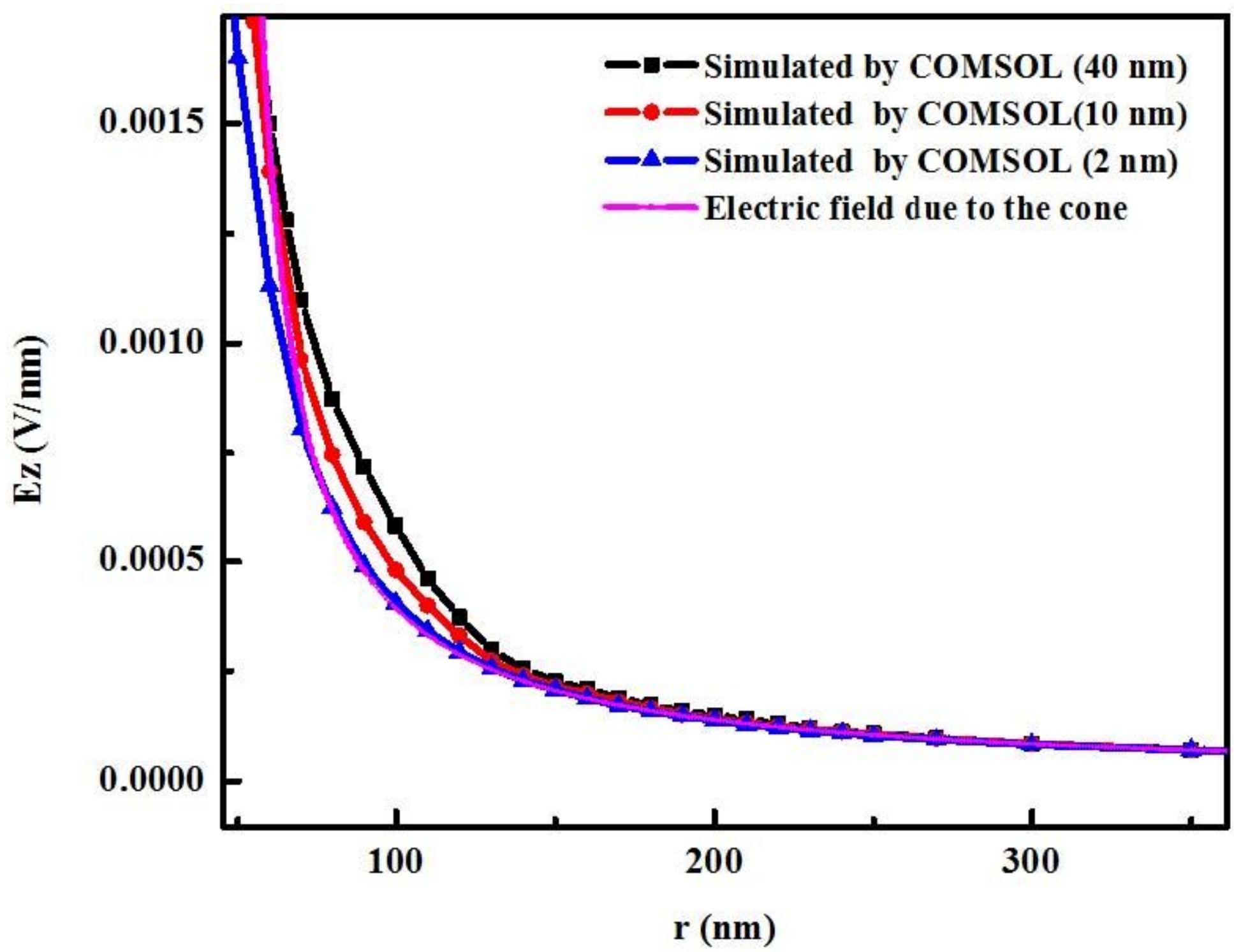

Figure 8

Simulated applied electric field of the AFM tip in 2, 10, $40 \mathrm{~nm}$ films by COMSOL (points-line) and the cone electric field (Eq. 5) (solid line). The tip radius is $60 \mathrm{~nm}$ (tip \#1). (See supporting information.)

\section{Supplementary Files}

This is a list of supplementary files associated with this preprint. Click to download.

- SupplementaryFinal.pdf 